\title{
Nilai-nilai Pendidikan dari Q.S. Fushshilat Ayat 30-32 tentang Iman dan Istiqomah terhadap Pendidikan Akidah
}

\author{
Riska Astyani*, Agus Halimi \\ Prodi Pendidikan Agama Islam, Fakultas Tarbiyah dan Keguruan, Universitas Islam \\ Bandung, Indonesia.
}

*riskaastyani2103.ra@gmail.com, aalepishamili@gmail.com

\begin{abstract}
Humans were created by Allah in a state of having the nature of Allah or the potential to know Him, force Him, and admit that there is no God but Allah. Therefore, humans are required to be able to develop this potential optimally and not deviate from their nature. However, still widespread practice of shirk that befell the Muslims. Even more so many Muslims who apostatize. Even though Allah advised in Q.S. Fushshilat verses 30-32 to establish the position (istiqomah) in the words "Our God is Allah", which contains the pledge of one of shahada sentences namely "Asyhadu Allaa Ilaaha Illallah". The method used in this study was a method of descriptive analysis with a library research by collecting data relating to the discussion. The result obtained from this study are: the essence that contained in Q.S. Fushshilat verses 30-32 are: (a) Faith is a solid foundation for a person who are istiqomah, (b) A person who istiqomah has an optimistic nature in life, (c) Aqeedah education needs to be instilled early on in order to form an istiqomah attitude. Educational values from Q.S. Fushshilat verses 30-32 are 1) Faith which is the foundation of the Istiqomah likened a good tree in Q.S. Ibrahim verses $24-25,2$ ) Characteristics of people who istiqomah that is optimistic, they are not afraid and also do not worry in facing the future both concerning about worldly and hereafter. Because their faith is so strong, 3) Parents are responsible for the education/strengthening of a child's faith from an early age in the development of the nature/potential of their Tauhid..
\end{abstract}

Keywords: Q.S. Fushshilat, Faith, Istiqomah, Aqeedah Education

\begin{abstract}
Abstrak. Manusia diciptakan oleh Allah dalam keadaan memiliki fitrah Allah atau potensi untuk mengetahuiNya, mengesakan-Nya, dan mengakui bahwa tidak ada tuhan melainkan Dia. Karena itu, manusia dituntut untuk dapat mengembangkan potensi tersebut secara optimal dan tidak menyimpang dari fitrahnya. Namun masih maraknya praktek kesyirikan yang menimpa Kaum Muslimin. Terlebih lagi banyak Kaum Muslimin yang murtad. Padahal Allah berpesan di dalam Q.S. Fushshilat ayat 30-32 untuk meneguhkan pendirian (istiqomah) dalam perkataan "Tuhan kami adalah Allah", yang mengandung ikrar salah satu kalimat syahadat yaitu "Asyhadu Allaa Ilaaha Illallah". Metode yang digunakan dalam penelitian ini adalah metode analisis deskriptif dengan jenis kepustakaan yaitu dengan cara mengumpulkan data dengan menggunakan buku-buku, literatur, bahan pustaka yang menunjang dan ada keterkaitan dengan pembahasan peneliti. Hasil dari penelitian ini adalah esensi yang terkandung dalam ayat Q.S. Fushshilat yaitu: (1) Iman merupakan fondasi yang kokoh bagi seorang yang beristiqomah, (2) Seorang yang istiqomah memiliki sifat yang optimis dalam menjalani kehidupan, (3) Pendidikan Akidah perlu ditanamkan sejak dini agar terbentuk sikap istiqomah. Nilai-nilai pendidikan dari Q.S. Fushshilat ayat 30-32 yaitu 1) Iman yang menjadi fondasi dari keistiqomahan diibatkan pohon yang baik dalam Q.S. Ibrahim ayat 24-25, 2) Karakteristik orang yang beristiqomah yaitu optimis, ia tidak takut dan tidak pula khawatir dalam menghadapi masa depan baik yang menyangkut keduniaan maupun keakhiratan. Karena imannya yang begitu kokoh, 3) Orang tua bertanggung jawab dalam pendidikan/penguatan akidah anak sejak dini dalam pengembangan fitrah/potensi tauhidnya.
\end{abstract}

Kata Kunci: Q.S. Fushshilat, Iman, Istiqomah, Pendidikan Akidah 


\section{A. Pendahuluan}

Manusia diciptakan oleh Allah dengan membawa fitrah atau potensi tauhid. Sebagaimana firman Allah dalam Q.S. Ar-Ruum ayat 30, yang artinya: "Hadapkanlah wajahmu dengan lurus pada agama Islam yang sesuai dengan fitrah Allah karena Allah telah menciptakan manusia menurut fitrah itu. Tidak ada perubahan pada ciptaan Allah. Itulah agama yang lurus, tetapi kebanyakan manusia tidak mengetahui." Kemudian disebutkan pula dalam sebuah hadits, Nabi SAW. bersabda:

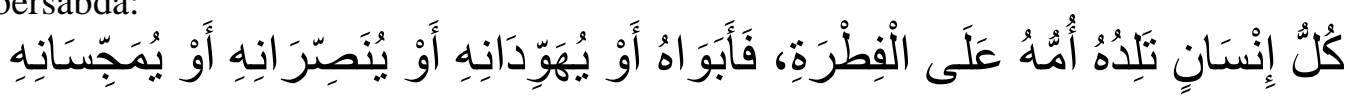

"Setiap manusia dilahirkan ibunya di atas fitrah. Kedua orang tuanya yang menjadikannya Yahudi, Nasrani, atau Majusi” (HR. Muslim)

Maka berdasarkan ayat dan hadits di atas, pada fitrahya manusia diciptakan beragama Islam. Orang tua merekalah yang memberi "cap" agama selain Islam. Tetapi bukan berarti orang-orang yang lahir dari orang tua yang bukan Islam, maka ia otomatis tidak mewarisi fitrahnya yang beragama Islam. Karena apabila Allah memberikan hidayah dan dengan lapang dada ia menerima hidayah tersebut, maka ia akan kembali kepada fitrahnya sebagai seorang Muslim dengan menjadi mualaf.

Kemudian yang menjadi permasalahan adalah terdapatnya orang-orang yang mengotori fitrah tersebut. Contohnya ketika periodesasi dakwah Rasulullah di Mekah, umumnya masyarakat Arab pada masa itu sudah menyimpang jauh dari ajaran agama tauhid yang telah diajarkan oleh para nabi dan rasul terdahulunya. Sebagaimana disebutkan oleh Mubasyaroh (2015 : 387), kondisi bangsa Arab sebelum kedatangan Islam, masih diwarnai dengan penyembahan berhala, walaupun mereka tidak mengakui berhala sebagai Tuhan mereka, tetapi berhala-berhala tersebut hanya diyakini sebagai wasilah agar mampu mendekatkan mereka kepada Tuhan dan menghubungkan mereka kepada-Nya. Sehingga dakwah yang pertama kali dilakukan Rasulullah saat itu difokuskan pada bidang ketauhidan.

Di Indonesia, praktek kesyirikan ini juga ternyata banyak dilakukan, misalnya memberikan sesajen ketika panen yang diyakini sebagai rasa terima kasih kepada "Dewi" yang dianggap telah berjasa menyuburkan tanah mereka, sehingga menjadikan hasil panen mereka berlimpah. Ada pula sesajen yang diberikan ketika ada pernikahan, hendak membuat rumah, dan juga untuk tolak bala. Kemudian keyakinan terhadap Nyi Roro Kidul yang disebut sebagai "penguasa" Laut Selatan. Mereka memberikan tumbal berupa kepala kerbau yang diyakini agar laut tersebut tidak ngamuk ketika para nelayan berlayar. Ada pula, yang memohon kepada pohon keramat atau kuburan supaya diberikan kekayaan.

Kemudian yang lebih memprihatinkan lagi adalah banyak diantara Kaum Muslimin yang murtad dan mengkonversi agamanya ke selain Islam. Menurut Anton (Prasetyo, 2016), saat menghadiri soft launching Badan Koordinasi Penanggulangan Penodaan Agama (Bakorpa) di Tebet, Jakarta Selatan, pada Jum'at, 15 April 2016 malam, bahwa perkembangan Kristen terpesat di dunia ada di Indonesia, dan pemurtadan besar-besaran muslim ada di negara muslim terbesar di dunia yaitu Indonesia.

Menurut Prasetyo (2016), yang kerap menjadi pintu masuk pemurtadan tidak akan lebih dari dua faktor, pendekatan ekonomi dan perkawinan antar agama. Jarang terjadi muslim yang murtad hanya karena mempertanyakan eksistensi Tuhan dan sistem nilai yang diajukan oleh Islam. Di sisi lain, orang yang menjadi mualaf karena perkawinan pun, banyak diantaranya setelah bercerai, ia kembali lagi ke agama awalnya. Bahkan ada pula yang bolak-balik keyakinan setelah mendapatkan pasangan yang baru.

Berdasarkan latar belakang di atas, maka perumusan masalah dalam penelitian ini yaitu "Bagaimana nilai-nilai pendidikan dari Q.S. Fushshilat ayat 30-32 tentang Iman dan Istiqomah terhadap Pendidikan Akidah?"

Adapun tujuan dilakukan penelitian ini yaitu: (1) untuk memperoleh hasil pemikiran Mufasir tentang kandungan Q.S. Fushshilat ayat 30-32; (2) untuk menemukan esensi yang terkandung dalam Q.S. Fushshilat ayat 30-32; (3) untuk menemukan teori-teori para ahli tentang Pendidikan Akidah dan Istiqomah; dan (4) untuk memperoleh nilai-nilai pendidikan dari Q.S. Fushshilat ayat 30-32. Adapun metode yang digunakan dalam penelitian ini adalah metode 
analisis deskriptif dengan jenis kepustakaan yaitu dengan cara mengumpulkan data dengan menggunakan buku-buku, literatur, bahan pustaka yang menunjang dan ada keterkaitan dengan pembahasan peneliti.

\section{B. Landasan Teori}

Menurut Al-Mubarakfuri (dalam Tafsir Ibnu Katsir, 2006 : 105-108) menyampaikan orangorang yang mengatakan: 'Rabb kami ialah Allah,' kemudian mereka meneguhkan pendirian mereka," yakni, mereka yang memurnikan niat dalam beramal, hanya karena Allah. Mereka pun melakukan ketaatan kepadaNya sesuai dengan syari'at yang Dia berlakukan bagi mereka.

Muslim meriwayatkan di dalam kitab Shahihnya, juga An-Nasa'i dari Sufyan bin 'Abdillah ats-Tsaqafi, ia berkata, "Saya berkata, 'Wahai Rasulullah, katakanlah kepadaku satu ucapan di dalam Islam, di mana saya tidak bertanya tentangnya setelah ini kepada selain engkau.' Beliau bersabda;

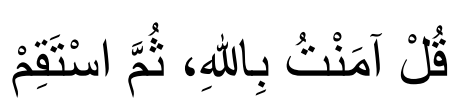

"Katakanlah, 'Saya beriman kepada Allah,' Kemudian teguhkanlah pendirianmu." Dan Sufyan mengatakan hingga keseluruhan hadits.

Kemudian Allah mengabarkan bahwa malaikat akan turun kepada mereka (orang yang istiqomah dalam perkataan "Rabb kami ialah Allah"), kemudian berkata kepada mereka "Janganlah kamu merasa takut", yaitu kepada perkara perihal akhirat, dan "Janganlah kamu merasa sedih," atas perkara dunia yang ditinggalkan, berupa anak, istri, harta benda, dll. Sebab Allah akan memberikan penggantinya yaitu diperolehnya surga yang telah dijanjikan Allah kepada mereka.

Kemudian para malaikat pun berkata bahwa mereka adalah pelindung-pelindung atau wali-wali orang-orang mukmin, yakni teman di dalam kehidupan dunia, yang meluruskan, membimbing dan menjaga mereka dengan perintah dari Allah. Begitu pula, malaikat akan bersama mereka di akhirat. Malaikat akan menenangkan mereka dari ketakutan di dalam kubur dan ketika ditiup Sangkakala, menenteramkan mereka pada hari Kebangkitan dan pengumpulan, mendampingi mereka di jembatan ash-Shiraathul Mustaqim, dan mengantarkan mereka menuju Surga, negeri yang penuh kenikmatan. Karena di dalam surga mereka akan memperoleh apa yang mereka inginkan dan apa yang mereka minta, yaitu sebagai jamuan, karunia, dan anugerah dari Dzat Yang Maha Mengampuni dosa-dosa, Dzat Yang Maha Menyayangi, dan Yang Maha Penyantun.

Berdasarkan penjelasan tafsir di atas, Q.S. Fushshilat ayat 30-32 berarti merupakan kabar gembira atau balasan bagi orang-orang yang bertauhid dan beristiqomah.

Menurut UU RI No. 20 tahun 2003 tentang Sistem Pendidikan Nasional Bab I, pasal 1, ayat 1, dijelaskan bahwa pendidikan adalah usaha sadar dan terencana untuk mewujudkan suasana belajar dan proses pembelajaran agar peserta didik secara aktif mengembangkan potensi dirinya untuk memiliki kekuatan spiritual keagamaan, pengendalian diri, kepribadian, kecerdasan, akhlak mulia serta keterampilan yang diperlukan dirinya, masyarakat bangsa dan negara.

Adapun menurut Imam Ghazali (Rusn, 1998: 56), pendidikan yaitu proses memanusiakan manusia sejak masa kejadiannya sampai akhir hayatnya melalui berbagai ilmu pengetahuan yang disampaikan dalam bentuk pengajaran secara bertahap, di mana proses pengajaran itu menjadi tanggung jawab orang tua dan masyarakat menuju pendekatan diri kepada Allah sehingga menjadi manusia sempurna.

Menurut Akmansyah (2014: 161), menanamkan akidah yang benar yaitu dengan cara mengajarkan iman sejak dini. Rasulullah SAW. memberikan perhatian dalam mendidik akidah anak-anak para sahabat dan hal-hal terkait dengannya. Sebagaimana yang diriwayatkan dari Jundub ibn "Abd Allah r.a. yang menceritakan bahwa, "Saat kami bersama Nabi SAW., pada waktu itu kami masih remaja, kami belajar keimanan sebelum kami belajar Al-Qur'an, kemudian kami belajar Al-Qur'an sehingga bertambah (kuatlah) iman kami."

Selanjutnya menurut Shihab (Zuhdi, 2011: 115), istiqomah berasal dari kata qawama yang berarti berdiri tegak lurus. Kata istiqomah selalu dipahami sebagai sikap teguh dalam 
pendirian, konsekuen, tidak condong atau menyeleweng ke kiri atau ke kanan dan tetap berjalan pada garis lurus yang telah diyakini kebenarannya.

Menurut Al-Badr (2017: 27), pokok keistiqomahan adalah istiqomahnya hati. Imam Ahmad Rahimahullah meriwayatkan hadits Anas bin Malik r.a. dari Nabi SAW., beliau bersabda:

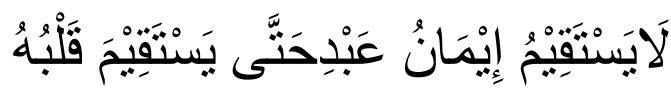

"Iman seorang hamba takkan pernah istiqomah sampai hatinya juga istiqomah."

Masih menurut Al-Badr (2017: 32), istiqomah yang dituntut dari seorang hamba adalah As-Sadad (bersikap lurus), jika ia tidak mampu maka ia muqorobah (berusaha mendekatinya).

\section{Hasil Penelitian dan Pembahasan}

Berdasarkan pendapat para mufasir mengenai Q.S. Fushshilat ayat 30-32, dapat ditarik beberapa esensi, yaitu: (1) Iman merupakan fondasi yang kokoh bagi seorang yang beristiqomah, (2) Seorang yang istiqomah memiliki sifat yang optimis dalam menjalani kehidupan, (3) Pendidikan Akidah perlu ditanamkan sejak dini agar terbentuk sikap istiqomah. Dengan demikian, analisis pendidikan terhadap esensi Q.S. Fushshilat ayat 30-32 adalah sebagai berikut:

\section{Iman merupakan fondasi yang kokoh bagi seorang yang beristiqomah}

Mukmin diibaratkan sebagai pohon yang baik, sebagaimana dalam Q.S. Ibrahim ayat 24-25 yang artinya, "Tidakkah kamu perhatikan bagaimana Allah telah membuat perumpamaan kalimat yang baik seperti pohon yang baik, akarnya kuat menghujam ke bumi, dan cabangnya menjulang ke langit. Pohon itu menghasilkan buah setiap waktu dengan seizin Tuhannya. Allah membuat perumpamaan itu untuk manusia agar mereka selalu ingat.” (Q.S. Ibrahim : 24-25). Mukmin diibaratkan sebagai pohon yang baik maksudnya seperti pohon yang memiliki akar yang kokoh, menghujam ke tanah, sebagai pondasi iman yang kokoh dan kuat, sehingga tidak mudah tumbang. Kemudian karena akarnya kuat, maka akan menumbuhkan batang yang kuat pula, besar dan menjulang tinggi ke langit, yaitu sebagai amalan atau perbuatan seorang mukmin yang dinaikan ke langit disebabkan oleh kalimat "Laa ilaaha illallaah". Serta pohon itu berbuah pada waktunya sebagai hasil dari perbuatan baik yang menjadikan orang mukmin berakhlak baik.

Kemudian dalam melaksanakan keistiqomahan, terdapat tiga hal yang harus terpenuhi yaitu istiqomah dalam niat atau hati, istiqomah dengan lisan atau dengan ucapan, dan istiqomah dengan perbuatan anggota tubuh. Menurut Al-Badr (2017 : 27), pokok keistiqomahan adalah istiqomahnya hati. Imam Ahmad Rahimahullah meriwayatkan hadits Anas bin Malik r.a. dari Nabi SAW., beliau bersabda:

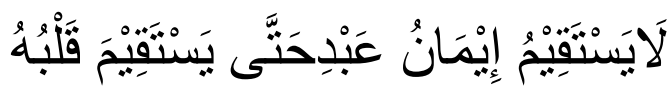

"Iman seorang hamba takkan pernah istiqomah sampai hatinya juga istiqomah."

Jadi, pokok keistiqomahan itu adalah istiqomahnya hati. Karena apabila hati itu baik, maka akan turut tegak (istiqomah) badannya. Karena sesungguhnya, hati itu adalah raja bagi anggota tubuh dan anggota tubuh adalah bala tentaranya. Apabila seorang raja istiqomah, maka akan istiqomah pula bala tentara dan rakyatnya (Al-Badr, $2017: 28$ )

Menurut Al-Badr (2017 : 29) pula, di dalam Shahihain dari Nu'man bin Basyir rahimahullahu beliau berkata: "Saya mendengar Rasulullah SAW. bersabda:

"Sesungguhnya di dalam jasad itu ada sekerat daging. Jika sekerat daging itu baik maka akan baik pula seluruh tubuhnya. Namun jika ia rusak, maka akan rusak pula seluruh tubuhnya. Ketauhilah bahwa sekerat daging itu adalah hati."

Maka berdasarkan penjelasan di atas, dapat disimpulkan bahwa iman merupakan fondasi yang kokoh bagi seseorang yang perlu dijaga keistiqomahannya. Karena iman itu letaknya ada di hati, maka hati harus selalu dijaga karena ia menjadi panglima dan anggota tubuh sebagai tentaranya. 


\section{Seorang yang istiqomah memiliki sifat yang optimis dalam menjalani kehidupan}

Menurut Al-Badr (2017 : 32) yang menyebutkan bahwa istiqomah yang dituntut dari seorang hamba adalah As-Sadad (bersikap lurus), maksudnya menepati (sesuai dengan) Sunnah. Maka dari itu, dituntut agar bersungguh-sungguh di dalam menepati petunjuk Nabi, manhaj, dan jalan beliau. Namun apabila belum sanggup maka hendaklah ia melakukan muqorobah (mendekati sunnah). Allah berfirman:

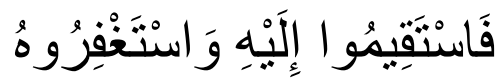

"Maka tetaplah kalian istiqomah di jalan-Nya dan mohonlah ampun kepadaNya." (Q.S. Fushshilat/41:6).

Penyebutan istighfar (permohonan ampun) setelah perintah untuk istiqomah menunjukkan bahwa seorang hamba itu biar bagaimanapun pasti memiliki kekurangan meski ia telah berusaha dengan sungguh-sungguh untuk bisa istiqomah. Beristigfar merupakan konsekuensi bertaubat lalu kembali lagi istiqomah (Al-Badr, $2017: 33$ )

Dengan kembali lagi istiqomah setelah bertaubat, maka keistiqomahan yang dimiliki seorang Muslim akan melahirkan sifat optimis di dalam dirinya. Karena orang yang istiqomah tidak akan berputus asa dari rahmat Allah dan selalu berusaha agar Allah mengampuni kesalahannya disebabkan memiliki kekurangan dalam keistiqomahannya.

Orang yang istiqomah akan optimis dalam mengarungi samudera kehidupan. Ia tidak akan merasa takut, khawatir, sedih, pesimis, dan mudah menyerah baik dalam hal keduniawian atau keakhiratan. Karena meskipun yang harus ia hadapi adalah tantangan hidup yang sangat berat, baginya Allah SWT. adalah sebaik-baiknya tempat bergantung, berlindung, dan yang meminta pertolongan.

\section{Pendidikan Akidah perlu ditanamkan sejak dini agar terbentuk sikap istiqomah}

Anak lahir di tengah keluarga dalam keadaan tidak tau dan tidak dapat berbuat apa-apa. Untuk memenuhi kebutuhannya pun ia membutuhkan bantuan orang lain (termasuk orang tuanya). Namun demikian, anak lahir membawa potensi/fitrah tauhid. Pembentukan manusia beriman kepada Allah menuntut adanya pendidikan keimanan sejak dini kepada anak, sebagai upaya penanaman nilai-nilai keimanan di dalam dirinya sehingga fitrah untuk beriman tersebut berkembang sesuai dengan tuntutan ajaran Islam.

Sejalan dengan pendapat Akmansyah (2014 : 161) bahwa Rasulullah SAW. memberikan perhatian dalam mendidik akidah anak-anak para sahabat dan hal-hal yang terkait dengannya. Rasulullah SAW., mengajarkan keimanan sebelum mereka mempelajari Al-Qur'an. Hal ini menunjukkan bahwa Rasulullah mendahulukan pembelajaran keimanan bagi anak sejak dini sebelum mempelajari Al-Qur'an. Sebagaimana diriwayatkan dari Jundub ibn 'Abd Allah r.a. yang menceritakan bahwa, "Saat kami bersama Nabi SAW., pada waktu itu kami masih remaja, kami belajar keimanan sebelum kami belajar Al-Qur'an, kemudian kami belajar AlQur'an sehingga bertambah (kuatlah) iman kami."

Pendidikan akidah/keimanan merupakan pondasi dalam pembentukan kepribadian muslim yang diinginkan, yaitu pribadi yang: (a) ikhlas beribadah kepada Allah semata; (b) memahami makna dan maksud ibadah dan tingkah laku hidup yang pada gilirannya akan mengantarkan anak kepada tujuan itu; (c) Menjauhi segala yang harus dijauhinya seperti perbuatan syirik yang mempengaruhinya. Dengan demikian dapat dikatakan bahwa penanaman nilai-nilai akidah/keimanan kedalam kepribadian anak melalui pendidikan keimanan sangat strategis dalam memperkokoh dan menetapkan azaz kepribadian anak sebagai muslim guna penyerahan yang ikhlas kepada Allah di dalam melaksanakan amar ma'ruf dan nahi munkar sebagai manifestasi sikap konsisten dalam keimanannya (Lubis, $2016: 70$ )

\section{Kesimpulan}

Berdasarkan hasil pemikiran para mufasir terhadap Q.S. Fushshilat ayat 30-32 esensi ayat tersebut yaitu: (1) Iman merupakan fondasi yang kokoh bagi seorang yang beristiqomah, (2) Seorang yang istiqomah memiliki sifat yang optimis dalam menjalani kehidupan, (3) Pendidikan Akidah perlu ditanamkan sejak dini agar terbentuk sikap istiqomah. 
Nilai-nilai pendidikan yang dapat diambil berdasarkan analisis pendidikan, yaitu: 1) Iman yang menjadi fondasi dari keistiqomahan karena pokok keistiqomahan itu adalah istiqomahnya hati, maka mukmin diibatkan pohon yang baik sebagaimana dalam Q.S. Ibrahim ayat 24-25, 2) Istiqomah yang dituntut dari seorang hamba adalah As-Sadad (bersikap lurus). Namun apabila belum sanggup maka hendaklah ia melakukan muqorobah (mendekati sunnah). Karakteristik orang yang beristiqomah yaitu optimis, ia tidak takut dan tidak pula khawatir dalam menghadapi masa depan baik yang menyangkut keduniaan maupun keakhiratan. Karena imannya yang begitu kokoh, 3) Orang tua bertanggung jawab dalam pendidikan/penguatan akidah anak sejak dini dalam pengembangan fitrah/potensi tauhidnya. Sebagaimana Rasulullah SAW. memberikan perhatian dalam mendidik akidah anak-anak para sahabat dan hal-hal yang terkait dengannya. Rasulullah SAW., mengajarkan keimanan sebelum mereka mempelajari AlQur'an.

\section{Daftar Pustaka}

[1] Akmansyah, M. (2014). Metode Pendidikan Aqidah dalam Tradisi Propetik Nabi Muhammad $S A W$. Jurnal Ijtimaiyya Vol. 7 No. 1. Tidak Diterbitkan

[2] Al-Badr, Abdurrazzaq al - 'Abbad. (2017). 10 Prinsip Meraih Istiqomah. Diterjemahkan oleh: Abu Salma Muhammad Rachdie, S.Si. dari judul asli "Asyru Qowa 'id fil Istiqomah”. AlWasathiyah wal I'tidal Digital Publishing: alwasathiyah.com. Tidak Diterbitkan.

[3] Al-Mubarakfuri, Syaikh Shafiyyur Rahman. (2006). Shahih Tafsir Ibnu Katsir. Bogor: Pustaka Ibnu Katsir

[4] Amiruddin, Aam. (2017). Al-Qur'an Al-Mu'asir. Cet. IV. Bandung: Khazanah Intelektual

[5] Lubis, Amir Hamzah. (2016). Pendidikan Keimanan dan Pembentukan Kepribadian Muslim. Jurnal Darul 'Ilmi Vol. 04, No. 01. Padangsidimpuan: Tidak Diterbitkan.

[6] Mubasyaroh. (2015). Karakteristik dan Strategi Dakwah Rasulullah Muhammad SAW. pada Periode Makkah. At-Tabsyir: Jurnal Komunikasi Penyiaran Islam Vol. 3 No. 2. STAIN Kudus: Tidak diterbitkan

[7] Prasetyo, Imam. (2016). Fenomena Murtadnya Dua Juta Orang Pertahun. Retrieved from https://www.google.com/amp/s/www.kompasiana.com/amp/imam.prasetyo4/fenomenamurtadnya-dua-juta-orang-pertahun_5743afaf8c7e610805649ecc diakses tanggal 03 September 2019 pukul 22:09

[8] Rusn, Abidin Ibnu. (1998). Pemikiran al-Ghazali tentang Pendidikan. Yogyakarta: Pustaka Pelajar

[9] Zuhdi, M. Harfin. (2011). Istiqomah dan Konsep Diri Seorang Muslim. Jurnal RELIGIA Vol. 14, No.1. Fakultas Syari'ah IAIN Mataram. Tidak Diterbitkan. 